\title{
Assessing intraplate earthquake hazards from satellite geopotential field observations
}

\author{
Ralph R. B. von Frese ${ }^{1}$, Jeong Woo Kim ${ }^{2,3}$, Orlando Hernandez ${ }^{1,4}$, Hyung Rae Kim ${ }^{5 *}$, and Mohammad F. Asgharzadeh ${ }^{1}$ \\ ${ }^{1}$ School of Earth Sciences, The Ohio State University, Columbus, OH, 43210, U.S.A. \\ ${ }^{2}$ Department of Geomatics Engineering, University of Calgary, Alberta, Canada \\ ${ }^{3}$ Department of Geoinformation Engineering, Sejong University, Seoul, Korea \\ ${ }^{4}$ Geosciences Department, Universidad Nacional de Colombia, Bogotá, Colombia \\ ${ }^{5}$ GEST, University of Maryland, Baltimore County at Planetary Geodynamics Lab., NASA/GSFC, \\ Greenbelt, MD, 20771, U.S.A.
}

(Received February 22, 2007; Revised November 6, 2007; Accepted November 12, 2007; Online published May 16, 2008)

\begin{abstract}
Satellite magnetic and gravity field observations provide important constraints on the poorly understood lithospheric properties of intraplate earthquakes because they map lateral long-wavelength contrasts in magnetization and density, respectively, related to petrological, structural, and thermal variations that help control the distribution of lithospheric stress. These anomalies are each a product of the vertically integrated physical property times the layer thickness. Thus, they constrain and enhance the geological utility of near-surface geopotential surveys, as well as seismic, GPS, and other geophysical observations that map the geological and dynamic properties of the lithosphere. To illustrate this synergy, we consider the influence of the US Transcontinental Magnetic Anomaly (TMA) on crustal stress and earthquake activity along the $38^{\text {th }}$ parallel. In another example, we compare crustal earthquake stress constraints from gravity and seismic observations of the US mid-continent and North Andes microplate where starkly contrasting plate tectonic forces operate.
\end{abstract}

Key words: Earthquake, hazards, gravity, magnetic, satellite data.

\section{Introduction}

Satellite-observed gravity and magnetic anomalies help greatly to expand our understanding of the plate tectonic properties of the crust and underlying mantle (e.g., Langel and Hinze, 1998). The crustal magnetic anomalies from NASA's Magsat mission in Fig. 1, for example, reveal unique perspectives in both space and time on the tectonic properties of the continents (von Frese et al., 1986). These prominent magnetic features of the continental plates are also verified and further detailed by ESA's recent Ørsted and CHAMP satellite observations (e.g., Purucker et al., 2002; Kim, 2002; Maus et al., 2006).

The Magsat anomalies in Fig. 1 were gridded to a common elevation $(Z=400 \mathrm{~km})$ and differentially reducedto-pole (DRTP) (e.g. von Frese et al., 1981a, 1982, 1997a; Arkani-Hamed, 2007). The DRTP adjustment centers the induced magnetic anomaly components over their lithospheric sources just like first vertical derivative gravity anomalies are centered on their subsurface density variations. Hence, DRTP magnetic anomalies most directly constrain complementary gravity, seismic, heat flow, and other source-centered geophysical data.

The DRTP crustal Magsat anomalies in Fig. 1 demonstrate remarkable continuity of the magnetic effects of the

\footnotetext{
*Now at Dept. of Geoenviron. Sci., Kongju Univ., Kongju, Korea.
}

Copyright (c) The Society of Geomagnetism and Earth, Planetary and Space Sciences (SGEPSS); The Seismological Society of Japan; The Volcanological Society of Japan; The Geodetic Society of Japan; The Japanese Society for Planetary Sciences; TERRAPUB.
Paleozoic cratons across the rifted margins of the continents. Langel and Hinze (1998) review the Magsat anomalies that have been quantitatively investigated in the context of complementary geological and geophysical data. The prominent positive Kursk Magnetic Anomaly (KMA in Fig. 1) over Russia, for example, appears to reflect thickened crustal effects (Taylor and Frawley, 1987). Specifically, the seismic refraction observations in Fig. 2 suggest that thickened magnetic crust displaces approximately 10$\mathrm{km}$ of relatively non-magnetic upper mantle beneath the KMA.

The enigmatic prominent positive Transcontinental Magnetic Anomaly (TMA) of the US in Fig. 1 is a further example that may reflect crustal thickness variations. The TMA, which Fig. 3 presents in greater detail, extends from the southwest near the Colorado Plateau to the east central US. It lies roughly along the $38^{\text {th }}$ parallel lineament that also defines prominent regional trends of crustal fractures in aeromagnetic data (Fuller, 1964) as well as major ore deposits (Heyl, 1972). Thicker crust characterizes the TMA (von Frese et al., 1982; Schnetzler and Allenby, 1983; Starich et al., 1985), and its eastern portion in Kentucky and Tennessee involves mafic crustal rocks associated with a Middle Precambrian rift (Mayhew et al., 1982).

In the following sections, we explore the TMA's relationship to crustal stress and density variations. We also contrast crustal earthquake constraints from gravity and seismic observations of the US mid-continent and the North Andes microplate that are subject to starkly different tectonic forces. 


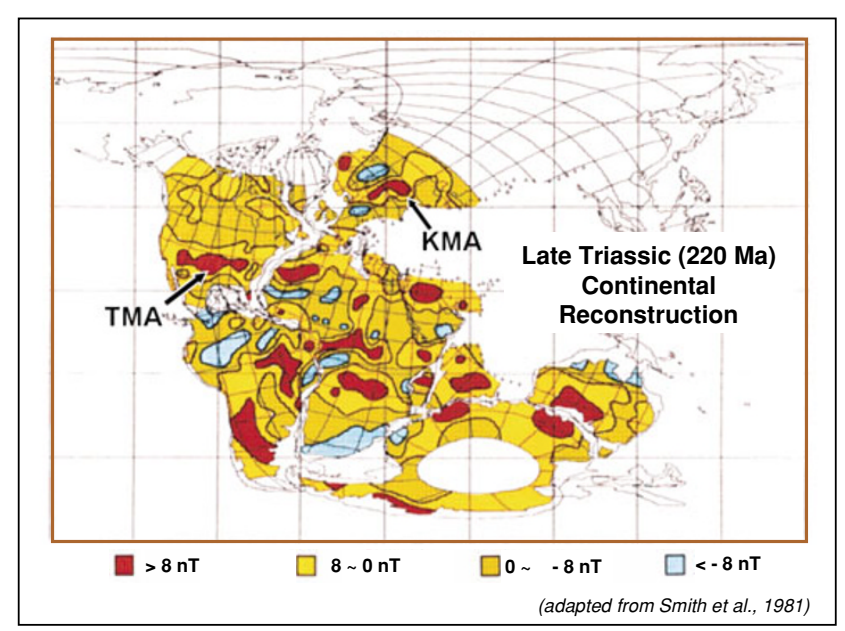

Fig. 1. Pangea and Magsat scalar total magnetic field anomalies reduced to $400 \mathrm{~km}$ altitude $(Z)$ and to $60,000 \mathrm{nT}$ radial polarization intensity featuring the Transcontinental Magnetic Anomaly (TMA) of the US and the Kursk Magnetic Anomaly (KMA) of Russia. The Late Triassic continental reconstruction map was adapted from Smith et al. (1981).

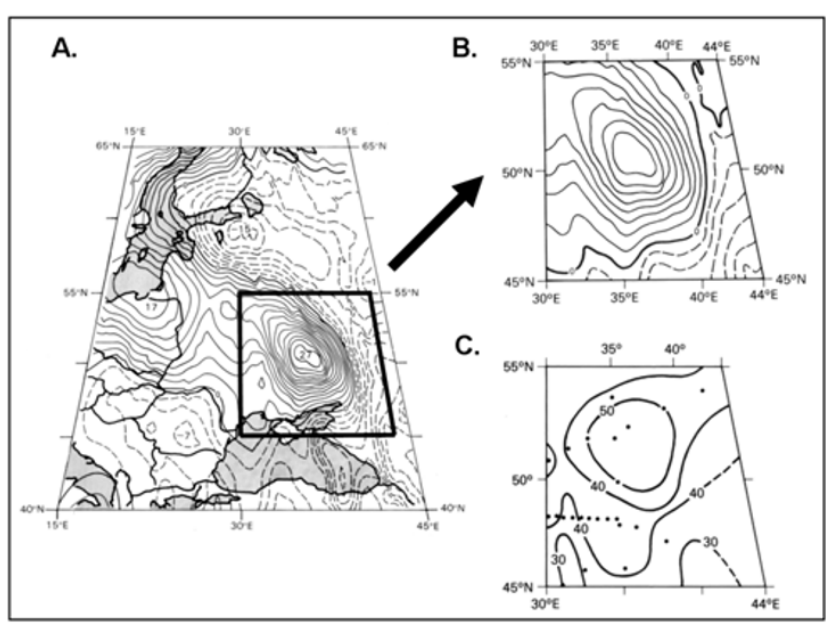

Fig. 2. (A) The Kursk Magnetic Anomaly (KMA) in nT involves (B) the component over Russia, which is strongly correlated with (C) Moho depth estimates in $\mathrm{km}$ from seismic refraction soundings (dots) that suggest an underlying 15-20 km thickening of the crust.

\section{Satellite Geopotential Anomaly/Tectonic Asso- ciations}

In Figs. 1 and 3, two minima partially breach and constrict the positive TMA towards its western and eastern margins. Both minima have significant concentrations of earthquakes (Fig. 3) even though the minima reflect different tectonic conditions. The western minimum, for example, reflects thinned magnetic crust due to increased heat flow in the Cenozoic Rio Grand rift. The eastern breach, on the other hand, is due to a paleo-rift structure underlying the Mississippi River embayment (von Frese et al., 1981b; Thomas, 1984). Reactivation of the northern end of this ancient aulacogen resulted in the 1811-1812 series of massive New Madrid earthquakes. Since 1812, however, considerable urbanization of the mid-continent has proceeded with dangerously little or no regard for the great hazards that large intraplate earthquakes can pose. Earthquakes are

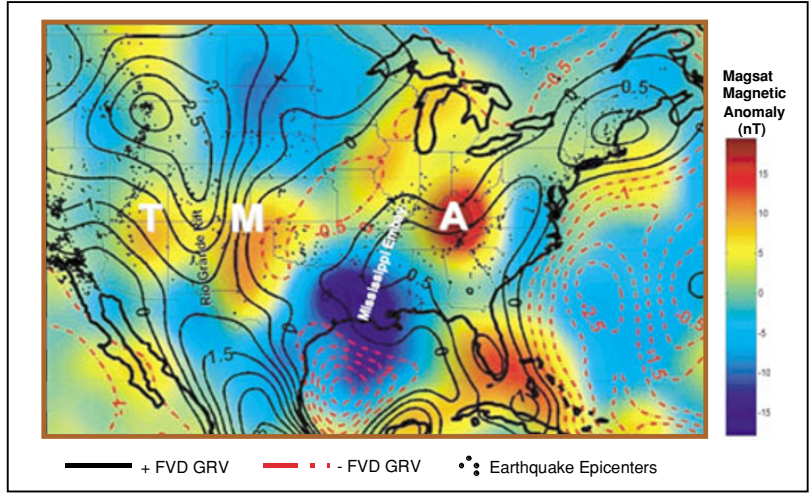

Fig. 3. Color representation of DRTP Magsat anomalies (nT) at $400 \mathrm{~km}$ elevation. The TMA is marked by three prominent maxima along the $38^{\text {th }}$ parallel. The superposed line contours give the first vertical derivative free-air gravity anomalies (nGals/m) at $400 \mathrm{~km}$ altitude. Red dashed contours indicate negative derivative anomalies and black solid contours give the positive anomalies. Black dots mark epicenters for mostly US earthquakes since 1973 from the USGS/NEIC catalogue.

also prominently concentrated in the warm, thinned magnetic crust along the western margin of the TMA. They also cluster along the eastern TMA margin where the magnetic anomaly sources occur related to tectonic events of the Appalachian orogen and exotic terrains left behind during the breakup of Pangea (Williams and Hatcher, 1983).

The crustal setting of the TMA also involves density contrasts and related gravity anomalies that further constrain its geologic interpretation. Poisson's relation gives the quantitative basis for correlating gravity and magnetic anomalies (e.g., von Frese et al., 1982, 1997a). Accordingly, for a source with both density and induced magnetization, the source's magnetization-to-density ratio essentially relates its vertical derivative gravity anomaly to its reducedto-pole magnetic anomaly. Hence, by Poisson's relation, these anomalies are spatially coincident when the magnetization is entirely induced, while the level at which they do not conform can reflect the degree of remanence in the magnetic anomaly (Cordell and Taylor, 1971).

Figure 3 compares the first vertical derivative EGM96 free-air gravity anomalies (Lemoine et al., 1998) with the DRTP Magsat anomalies for this synergism in the US midcontinent. The TMA maxima tend to correlate inversely with relative gravity minima to characterize possible regions of enhanced crustal thickness where the more magnetic, less dense crust displaces less magnetic, denser mantle (von Frese et al., 1982).

Inverse correlations of relative gravity maxima with magnetic minima, on the other hand, probably characterize regions of reduced crustal thickness, although the tectonic origins of these anomaly correlations may be quite different. For example, the inverse anomaly correlation along the Mississippi Embayment accounts for the regionally demagnetizing and density enhancing effects of a mantle rift pillow in the lower crust (von Frese et al., 1982). However, in the western TMA breach along the Rio Grand rift, regionally correlative relative gravity maxima and magnetic minima respectively reflect crustal inflation and the demagnetizing effects of anomalously heated crust (von Frese et 


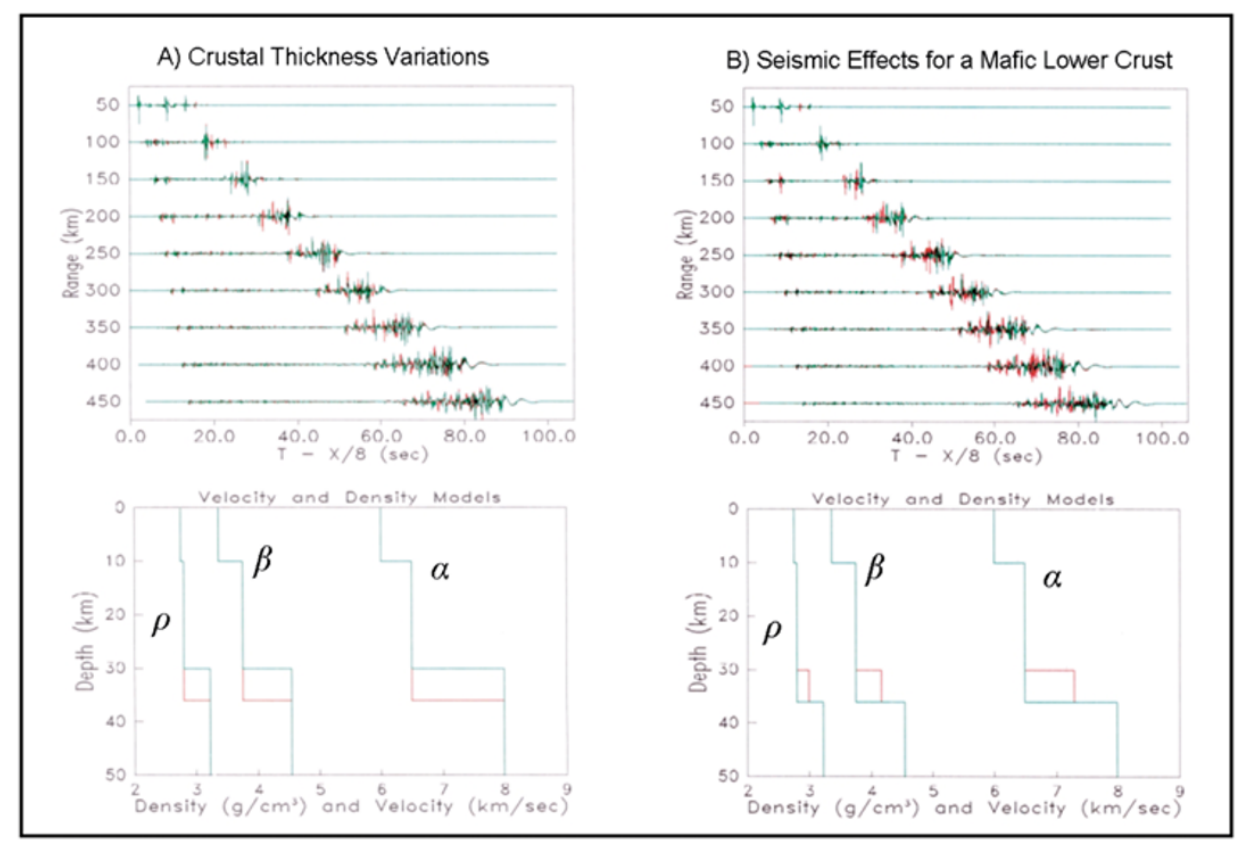

Fig. 4. Synthetic vertical displacement seismograms (upper) calculated for the differential lithospheric models (lower) in density ( $\rho$ ), and $P$-wave ( $\alpha$ ) and $S$-wave $(\beta)$ velocities that correspond to (A) deepening the Moho from $30 \mathrm{~km}$ and (B) adding a mafic rift component to the lower crust.

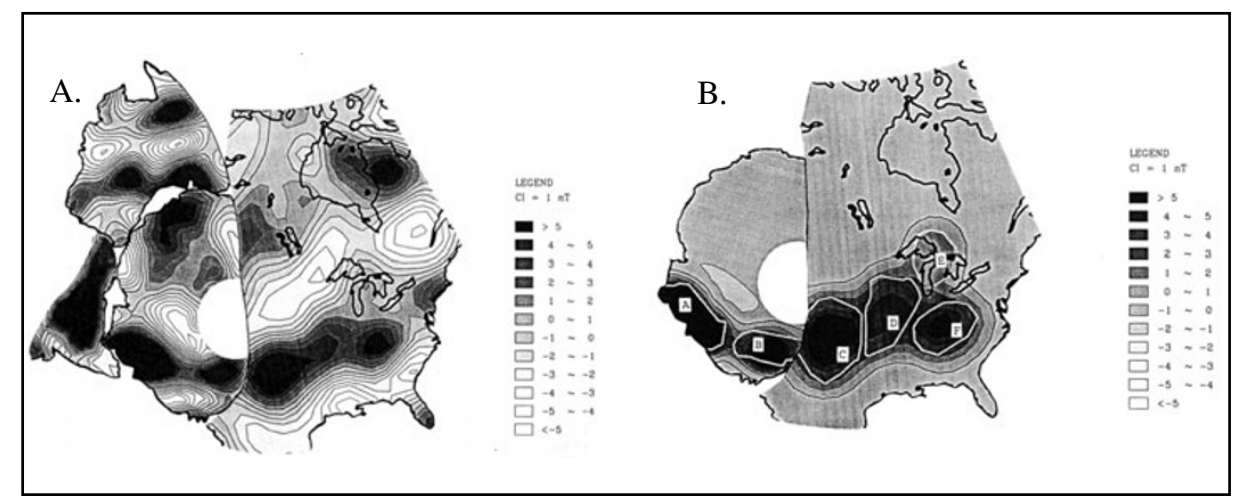

Fig. 5. (A) DRTP Magsat anomalies at $400 \mathrm{~km}$ elevation for the postulated Southwest US-East Antarctic (SWEAT) reconstruction in the Late Proterozoic (Moores, 1991). (B) Modeled DRTP magnetic anomalies have superposed lateral boundaries of inferred crustal thickness variations with magnetization contrast $0.6 \mathrm{~A} / \mathrm{m}$. The polygonal flat-topped and bottomed bodies were modeled at $400 \mathrm{~km}$ altitude in spherical-Earth coordinates with the following body(thickness, depth-to-bottom)-parameters in $\mathrm{km} \Rightarrow \mathrm{A}(20,50) ; \mathrm{B}(12,50) ; \mathrm{C}(27,50) ; \mathrm{D}(20,35) ; \mathrm{E}(12,35) ; \mathrm{F}(27,45)$.

\section{al., 1982).}

Seismic constraints obviously can greatly help to differentiate between competing lithospheric hypotheses for the TMA. Digital seismograms from the Long Range Seismic Measurements (LSRM) network are available (Gupta and McLaughlin, 1987), but the ray path coverage is relatively incomplete in many parts of the mid-continent. The projected deployment of the USArray in the mid-continent (e.g., Levander, 2003; Owens and Fowler, 2003; Meltzer, 2003) will provide improved 3D seismic coverage to augment the LRSM data considerably.

Figure 4 gives two examples of how even simple 1D inversions of digital waveform data from mid-continent earthquakes can facilitate the crustal interpretation of satellite geopotential field observations. The upper inserts show regional synthetic seismograms (e.g., Olsen and Braile, 1981; Bouchon, 1982; Campillo et al., 1984; Kennett, 1985; Braile and Chiang, 1985) for some simple crustal models that can reflect components of the mid-continent satellite altitude magnetic and gravity anomalies. These synthetic seismograms were computed using a full wavenumber integration method that includes all reverberations, surface reflections, and surface waves. The maximum frequency of the calculated seismograms was $5 \mathrm{~Hz}$ since the Nyquist frequency of the LRSM short-period data is $10 \mathrm{~Hz}$. The response was peaked at $3 \mathrm{~Hz}$ to represent the peak response of most LRSM stations, but was not high-passed filtered so that the long-period response can also be seen. To preserve uniformity for the synthetic seismogram plots, a vertical strike-slip focal mechanism at an azimuth of $100^{\circ}$ from the fault plane was convolved with the Green functions for the velocity models considered in the lower inserts of Fig. 4. Since seismic attenuation is low in most of the central US (Gupta and McLaughlin, 1987), quality factors of $Q>500$ were used in the calculations.

Figure 4(A) compares the calculated vertical displace- 


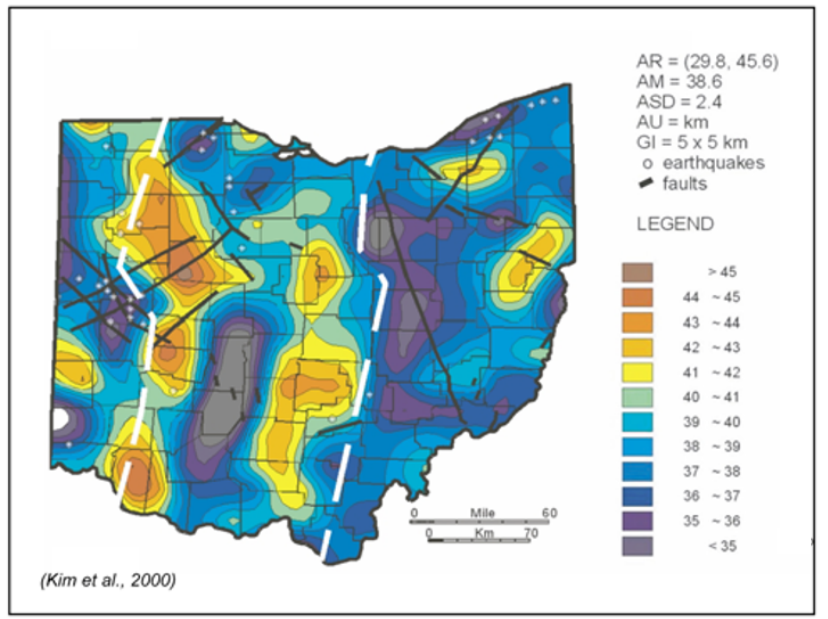

Fig. 6. Thickness variations $(\mathrm{km})$ of the Precambrian crust of Ohio with superposed faults and instrumentally determined earthquake epicenters.

ment seismograms for two crustal thickness models with contrasting density, and $P$-wave and $S$-wave velocity profiles. The two synthetic seismograms are superposed with the red portions corresponding to the differences in the seismic response for crustal thickening of $6 \mathrm{~km}$ relative to the green portions that correspond to the two-layer crust of $30 \mathrm{~km}$. The seismogram differences are particularly pronounced over source-to-receiver distances or ranges that are greater than about $200 \mathrm{~km}$.

Figure 4(B) demonstrates the effect of increasing the velocity structure in the lower $6 \mathrm{~km}$ of the crust such as may apply for the Mississippi Embayment aulacogen. The divergence of the calculated waveforms at increasing ranges suggests considerable sensitivity in the seismograms for this condition at distances between $150 \mathrm{~km}$ and $450 \mathrm{~km}$.

Figure 4 illustrates a few of the exciting prospects that the improved seismic coverage from the USArray offers for constraining crustal models of satellite geopotential anomalies. Of course, many other factors (e.g., sub-Moho velocity gradients, focal depth variations, lateral heterogeneities, etc.) also can cause differences in mid-continent earthquake seismograms. However, integrating the seismic data with gravity and magnetic crustal solutions clearly will help reduce crustal modeling ambiguities.

Moreover, satellite geopotential field anomalies provide unique windows on the evolution of their crustal sources as suggested in Fig. 1. The extension of the satellite anomalies across the rifted margins in continental plate reconstructions can also continue seismic images of the anomaly sources between tectonic plates. For example, Fig. 5 gives a Late Proterozoic reconstruction of Rodinia that suggests the thickened crustal components of the TMA may be related to comparable crustal features in East Antarctica (von Frese et al., 1997b). Therefore, seismic images of the crustal sources of the TMA from the USArray can have added value in helping to understand the crustal structures of East Antractica where seismic coverage is quite limited, as well as the development of Late Proterozoic crust in the US midcontinent.

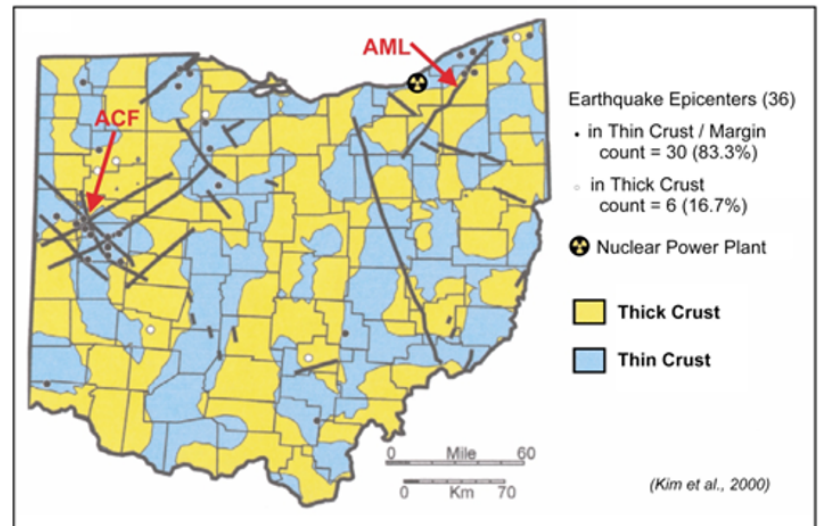

Fig. 7. Zero horizontal crustal curvature contours marking the edges of Precambrian crustal thickness variations. Basement feature abbreviations include ACF (Anna-Champaign Fault) and AML (Akron Magnetic Lineament)

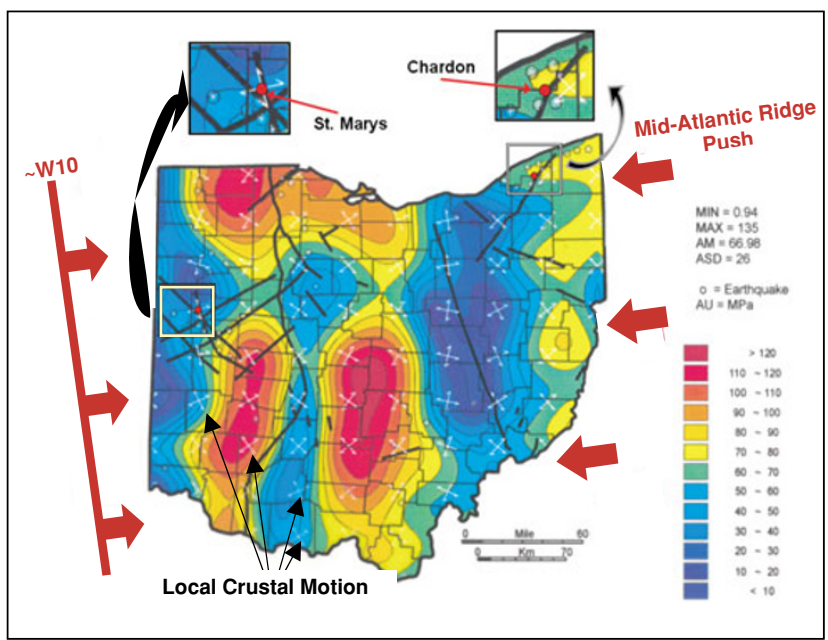

Fig. 8. Horizontal shear stress and local crustal motions inferred from crustal thickness variations and a superposed regional stress of $150 \mathrm{MPa}$ directed $\sim \mathrm{W} 10^{\circ} \mathrm{S}$ due to Mid-Atlantic ridge push.

\section{Crustal Stress Modeling of the US Mid- Continent}

The improved understanding of the relationships of regional magnetic and gravity anomalies to thickness variations of the North American crust can help quantify regional crustal stresses that may control intraplate tectonism. The crust presumably is seeking gravitational equilibrium (e.g., Artyushkov, 1973), which in the mid-continent may result largely from minimizing its thickness variations. Thus, the earthquake-benign thicker crust is mostly in tension and under pressure to flow into the surrounding earthquake-prone thinner crust that is mostly under compression. The regional magnetic and gravity anomaly correlations in Fig. 3 certainly tend to support this first order crustal stress model for North America.

Kim et al. (2000) gives an example of the influence of crustal thickness variations on mid-continent earthquakes. They developed the crustal thickness model of Ohio in Fig. 6 from the spectral correlation analysis of the related topographic gravity effects and free-air anomalies at $5 \mathrm{~km}$ 


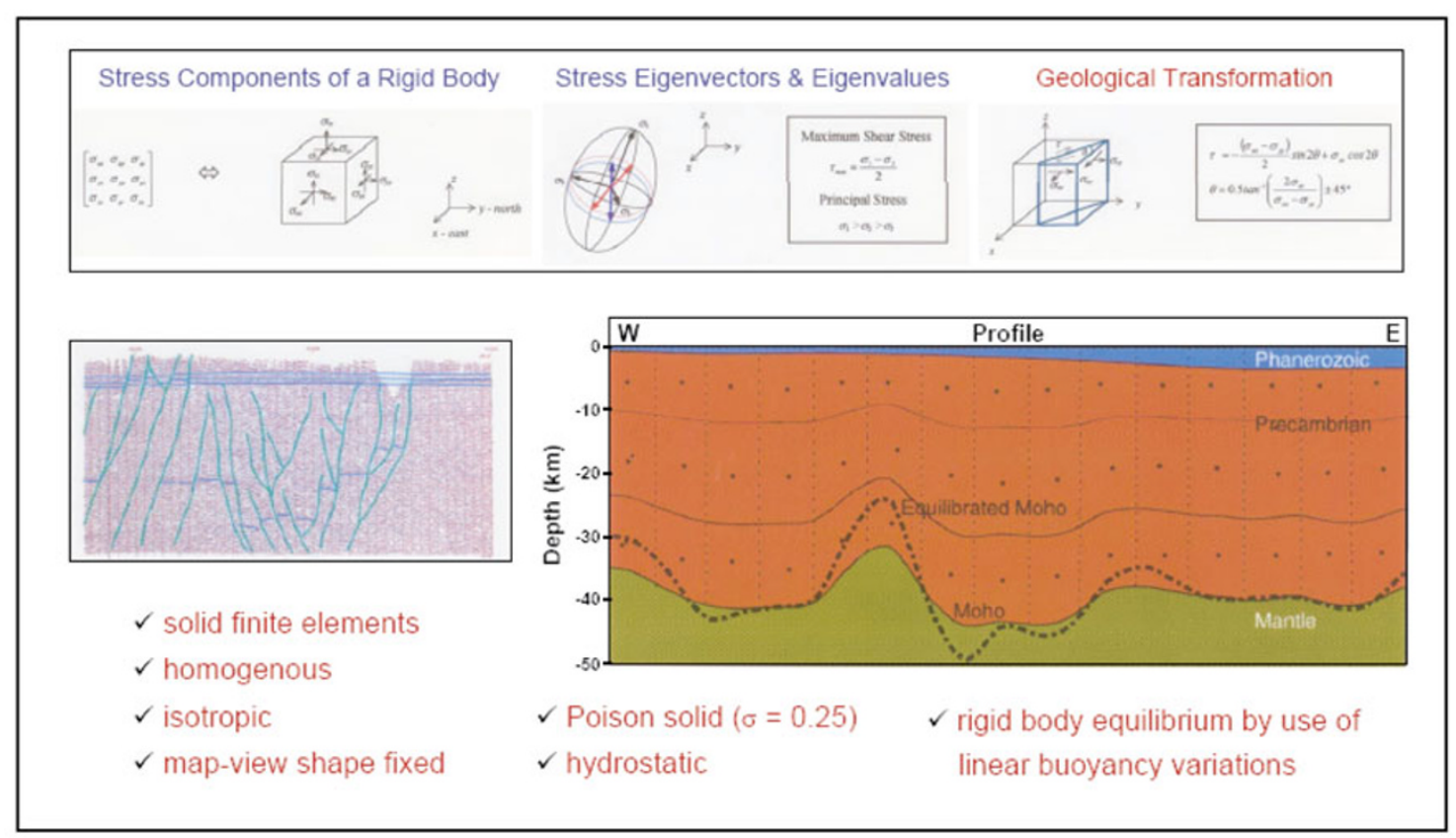

Fig. 9. Crustal stress modeling showing the analytical details (top panel) for assessing the horizontal shear stress along vertical fractures and faults indicated by the COCORP seismic section (lower left panel) over the finite element crustal mesh with the cross-section indicated in the bottom right panel.

altitude. Here, information from 149 basement wells from the Ohio Geological Survey was used to remove the gentle, SE-dipping cover of Phanerozoic sedimentary rocks to reveal better the Precambrian associations of the superposed instrumentally determined earthquake epicenters that all have focal depths within the crystalline basement rocks. Also superposed on this Ohio map are faults from analyses of some 200,000 boreholes in the Phanerozoic cover rocks (Hansen, 1996).

These relationships are more explicit in Fig. 7 where the zero horizontal curvature of Fig. 6 is plotted to mark the edges as slope changes between the thicker and thinner Precambrian crust of Ohio. Clearly, crustal thickness seems to influence the distribution of the earthquakes since more than $80 \%$ of them occur within or at the margins of the thinner compressive crust (Kim et al., 2000).

Figure 8 gives the horizontal shear stresses that we modeled by finite element analysis (e.g., Wagoner and Chenot, 2001) from the total thickness variations of Ohio's crust. Here, we modeled the stresses in the upper layer of a 3layered crust with standard values for the elastic rock properties and density. As shown in Fig. 9, the modeling assumed purely hydrostatic conditions with no deformation of the boundaries of the study area. The stresses were modeled for activating earthquakes along essentially vertical basement discontinuities (e.g., faults, fractures, intrusive contacts, etc.) that seem predominant in Ohio's uppermost crust according to the COCORP seismic reflection data (e.g., Pratt et al., 1989; Culotta et al., 1990) and the geopotential anomalies (Lucius and von Frese, 1988). The white orthogonal half-arrows in Fig. 8 give the two horizontal crustal motions that accommodate these shear stresses.

The alignments of earthquakes with Phanerozoic faults in northeastern, northwest central and west central Ohio clearly suggest that the faults also involve Precambrian basement components. The crustal motions modeled in Fig. 8 also include fault-aligned components that are consistent with the inferred first-motions of the larger instrumentally measured Ohio earthquakes.

For example, the Chardon event (Fig. 8) of 31 Jan. 86 was a 5.1 magnitude earthquake at a focal depth of $5 \mathrm{~km}$ in the basement rocks of northeastern Ohio (Wesson and Nicholson, 1986; Seeber and Armbruster, 1988). It occurred only a few days before the new Perry 1 nuclear power plant was to go on-line and generated ground accelerations that delayed the plant's start-up for about a year. The crustal stress modeling in Fig. 8 also predicts the right-lateral strike slip motion observed for this event (Seeber and Armbruster, 1988). These results are consistent with reactivation of the basement component of the NE-SW trending Akron lineament, which is also marked by a sharp linear magnetic anomaly gradient (e.g., Lucius and von Frese, 1988).

Another example is the St. Marys event of 16 Jul. 86 that was a 4.5 magnitude earthquake with a focal depth of $5 \mathrm{~km}$ in the basement rocks of west central Ohio (Fig. 8). It was produced in the Anna Seismogenic Zone that is the most active area of mid-continent seismicity outside of the New Madrid Seismic Zone. First motion studies (Schwartz and Christensen, 1988) indicate left-lateral strike slip motion for this event that is consistent with the stress modeling results in Fig. 8. This event was probably generated by reactivation of the basement component of the southeastwardly curving Anna-Champaign fault, which is also well defined by magnetic and gravity anomaly gradients (Lucius and von Frese, 1988).

Clearly the results in Fig. 8 when combined with basement fault and fracture information from drilling and geophysical data provide important new perspectives on the 
causes and effects of Ohio's earthquakes. However, the modeling shows that these results are only possible by including a roughly EW-directed regional 150-MPa crustal stress component as indicated by the red arrows in Fig. 8. Basement borehole stress studies across North America indicate that Mid-Atlantic Ridge push may provide this regional stress component (Zoback, 1992). The capacity of these results to account for the first motions of Ohio's earthquakes suggests that the local stress field is intimately connected to plate activity thousands of kilometers to the east, which of course is accessible to satellite geopotential field observations.

\section{Earthquake Hazards in Northwestern South America}

We now investigate the synergism between crustal thickness variations and earthquakes in the vigorously active multi-plate framework of northwestern South America. Figure 10 gives the Moho map that Hernandez and von Frese (2006) estimated from the spectral correlation analysis of the free-air and terrain gravity effects at $20 \mathrm{~km}$ altitude. The regional gravity perspective in this case represents the integration of terrestrial and airborne gravity survey observations with marine gravity data derived mostly from satellite altimetry estimates.

Figure 11 gives the zero curvature contours that estimate the edges of thickness variations with the yellow continental and oceanic regions marking crust thicker than about $34 \mathrm{~km}$ and $23 \mathrm{~km}$, respectively, whereas the blue regions delineate the thinner crustal components. For comparison, the plate boundaries are superposed along with crustal discontinuities that Hernandez and von Frese (2006) interpreted from the gravity data, and regional earthquake epicenters from the Advanced National Seismic System cata$\log$ (ANSS; USGS, 2006). For this study, we considered only earthquakes with hypocenter depths up to $60 \mathrm{~km}$ and Richter magnitudes $M=3-10$ for the period 1966-2006.

The earthquakes in Fig. 11 arise from plate motions along spreading oceanic ridges, converging subduction zones, colliding continental plate boundaries, and shearing oceanic transform faults. Pronounced seismicity marks the boundary zones of the Nazca, Caribbean, North American and South American plates, the North Andes, Panama and Costa Rica microplates, the Cocos-Nazca spreading system, and the intraplate discontinuities. It is hosted predominantly in the thicker crustal sections and along the inferred edges of the thickness variations. However, the thicker oceanic sections of the Nazca, Malpelo and Cocos ridges in the Pacific and the Beata ridge in the Caribbean are largely aseismic. Seismic quiescence also generally marks the thinner crustal regions, the Guiana craton, and the interior Nazca and Caribbean oceanic plates.

The subduction of the Nazca plate under the North Andes microplate stacked thrusted slices of crust that produced the Andes mountains. Lateral movements of these thrust slices in the welded continent generate minor, moderate, and major earthquakes at shallow, intermediate and deep depths that define the seismic corridors along the subduction zone and the Andes mountains in Fig. 11. The seismicity patterns and focal mechanism solutions are in general accord

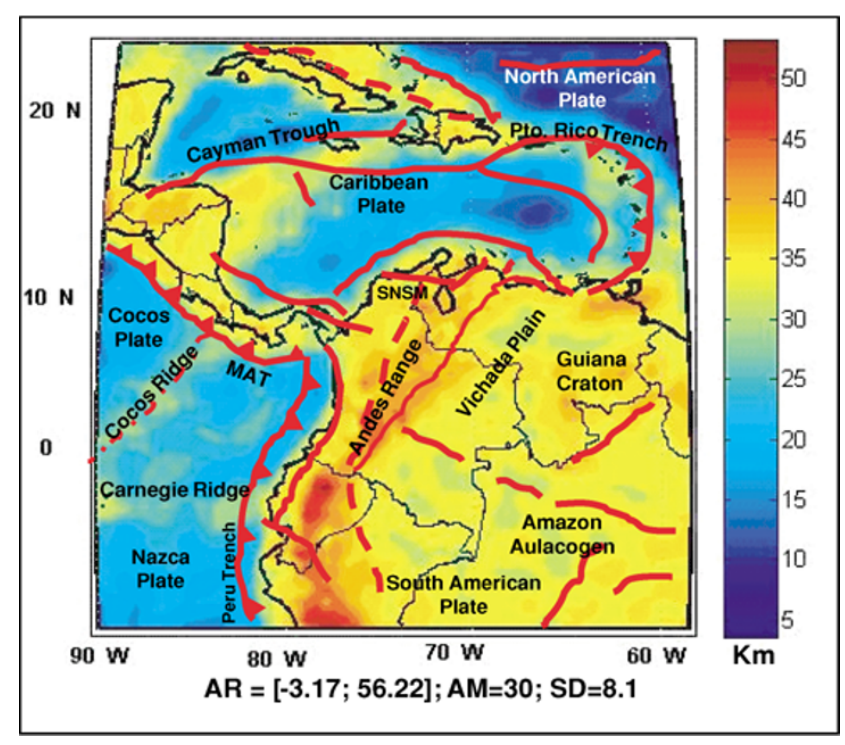

Fig. 10. Gravity MOHO estimates from Hernandez and von Frese (2006). Red lines represent plate boundary zones and crustal discontinuities. Map statistics include the amplitude range (AR) of ( $\min$; max) values, amplitude mean (AM), and standard deviation (SD). Crustal feature abbreviations include MAT (Mid-America Trench) and SNSM (Sierra Nevada of Santa Martha).

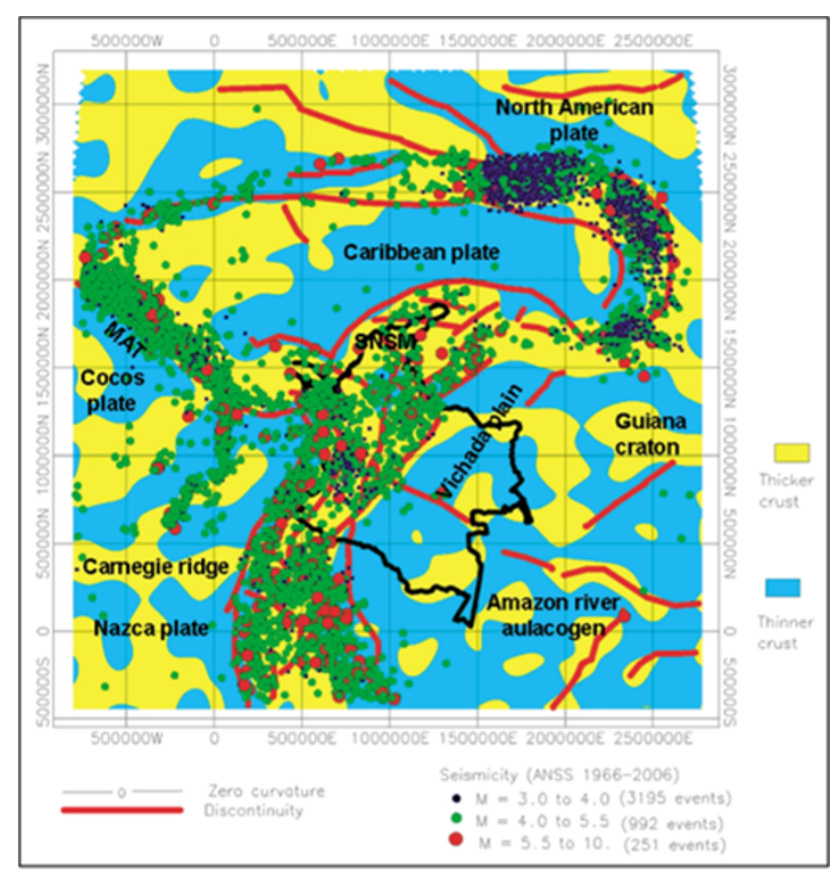

Fig. 11. Zero horizontal crustal thickness curvature with superposed earthquakes from the ANSS seismic catalog from 1966 to 2006 and crustal discontinuities interpreted from gravity anomalies.

with the easterly subduction of the Nazca plate beneath the Andes.

The broad pattern of intensive seismicity along the Middle American trench (MAT) is consistent with the low angle of inclination of the subducting Nazca and Cocos plates under the Central American continent. The relatively low seismicity along the Caribbean-North Andes plate boundary reflects the predominantly dextral lateral movement of the Caribbean plate with respect to the North Andes mi- 


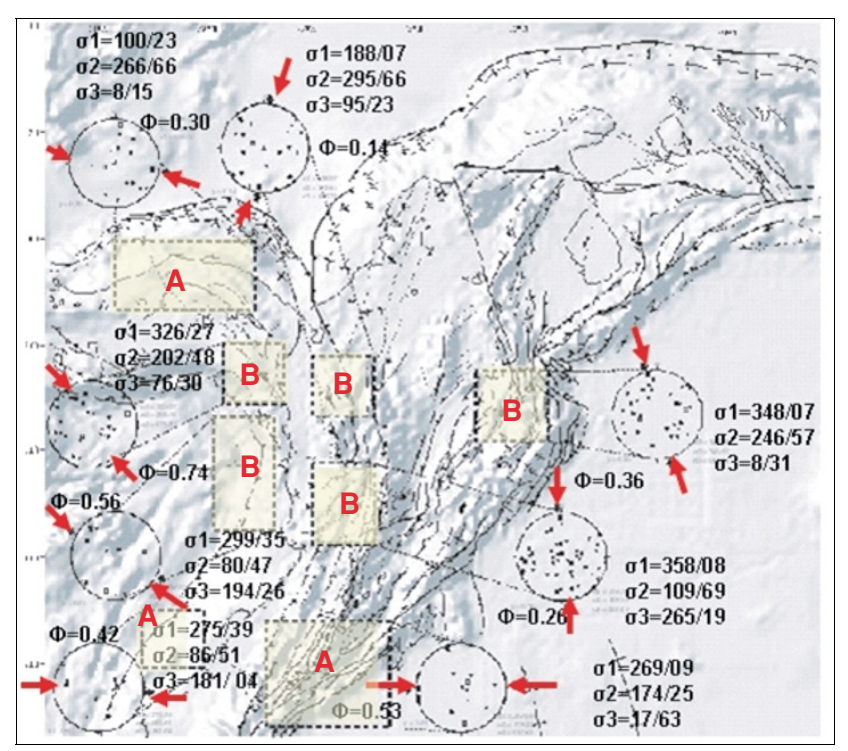

Fig. 12. Main stress axes determined by the Reches Method from 94 focal mechanism solutions of the Central Moment Tensor catalog (CMT) reported by Harvard University for the period 1976-2000 and event magnitudes $M 5.0$ (Vargas and Duran, 2005). The inferred fault planes are consistent with compressive plate boundary effects in regions (A), but not for regions (B) where prominent crustal thickness variations and related stresses occur.

croplate and South American plate. This movement may include minor incipient subduction compared to the subduction of the Nazca plate underneath the Andes mountains.

The broad arcuate seismic zone along the Lesser Antilles in Fig. 11 includes numerous events along the CaribbeanNorth American plate boundary, which dips westwards away from the underthrusting oceanic plate. Shallow, intermediate and deep focus earthquakes occur at progressively greater distances from this underthrusting. The trench is indicated by a belt of negative free-air anomalies, but its topographic expression is largely obscured by thick sediment fill derived from the Orinoco river of Venezuela. The seismic events are located in thicker oceanic crust associated with the doubling of the collisional oceanic crust. Focal mechanism solutions of the Lesser Antilles reflect regional compressive stress. However, local tensional stress marks the relatively thicker oceanic crust.

Intense seismicity characterizes the continent-continent collision boundary zone between the North Andes microplate and the South American plate in Fig. 11. Minor, moderate, and major seismic events have occurred along the Llanos Front fault historically and in the recent past. Shallow events are associated with tensional stresses of the subAndean thrust belt or fault zone, which is also located on a relatively thicker continental crust where additional tensional stresses may operate.

Minor and moderate earthquakes occur along the Galapagos spreading ridge and the Panama fracture zone in Fig. 11. Focal mechanism solutions indicate regional tensional events associated with plate accretion and strike-slip events where the ridges are offset by transform faults. However, the Panama fracture zone is located on relatively thinner oceanic crust that may locally concentrate compressional stress to mitigate these tensional effects.
The Southern Panama fault zone is a conservative plate boundary between the Nazca plate and Panama microplate. The plates are in tangential contact and little affected by subduction or accretion. Therefore, events along this fracture are rare as seen in Fig. 11.

The interior of the South American plate is mostly aseismic with relatively few minor, moderate and major historical and recent seismic events evident in Fig. 11. These events are located along some of the crustal discontinuities interpreted from the free-air gravity anomalies. Their occurrences suggest the presence of continental sutures in the South American plate with sporadic seismic activity. Although, these earthquakes are rare, they are important because they indicate the orientations of the stresses within the South American Plate.

For example, Fig. 12 gives the compressional stress regime of northwestern South America from analyses of the type of faulting or focal mechanisms of the instrumental earthquakes (Vargas and Duran, 2005). The converging margins along Costa Rica, Panama, and the North Andes show E-W oriented compressional stress, generating the relative movement of local tectonic blocks of the North Andes microplate. Shallow earthquakes associated with the Pacific subduction zone show NW-SE oriented compressional stress. E-W oriented vectors of displacement and compressional stress occur in southwestern Colombia. The deep seismicity in the Bucaramanga cluster reflects NNW-SSE oriented compressional stress associated with the Caribbean plate subducting under the North Andes microplate.

These focal mechanisms are generally consistent with modifications of the regional stresses by local stresses from the thickness variations of the crust. The continental earthquakes, for example, seem to reflect the effects of the plate tectonic stresses on the thicker, less competent and consolidated regions of the crust. The spectral correlations of the regional free-air and terrain gravity effects confirms that much of the relief of northwestern South America is isostatically disturbed (Hernandez and von Frese, 2006).

The inferred fault planes are consistent with the plate boundary zones in the local regions (A) of Fig. 12, but not in regions (B) that Vargas and Duran (2005) suggested may involve stress-modifying local compositional heterogeneities of the crust. These discrepancies, however, also can reflect significant local tension and compression contributions from the prominent thickness variations of the crust.

In Fig. 11, for example, tensional stress regimes of anomalously thickened crust from the multi-plate interactions appear to control the distributions of earthquakes up to hundreds of kilometers into the tectonic plate interiors. In general, integrating terrestrial gravity observations with satellite altimetry-derived marine gravity estimates for the crustal thickness variations yields new multi-plate tectonic perspectives on the earthquake zones and local ground motions of northwestern South America.

\section{Conclusions}

Regional gravity and magnetic observations facilitate understanding the structural and geological factors that give rise to intraplate regions of seismicity. These results contribute to understanding the strength profile and distribution 
of stress in the lithosphere that affect crustal strain transfer and large-scale continental deformation. These results clearly facilitate the combined use of regional geopotential fields and seismic array data to enhance our understanding of the intraplate tectonic features and evolution of the other continents as well. They help to resolve the rich fabric of tectonic provinces and structures that make up a continent. By comparing the regional geopotential anomalies of the continents in terms of the various continental plate reconstructions, we can extend constraints on the geopotential anomaly solutions through time to investigate the mechanisms by which continents are dispersed and reassembled, the crust and lithospheric mantle are related, and continental structure and deformation are connected.

Thickness variations of continental crust inferred from regional gravity and magnetic observations help account for the distribution and ground motions of intraplate earthquakes. Within the US mid-continent, earthquakes play out mostly in the compressive regimes of the thinner crustal regions, whereas in the more active crust of northwestern South America, plate tectonic stresses concentrate earthquakes predominantly in the tensional settings of the thicker crust.

Acknowledgments. We thank Dan O'Connell for computing the synthetic seismograms, Rob Wagoner for help in developing the crustal stress model of Ohio, and Patrick Taylor for Fig. 2. Research grants from the US National Science Foundation (OPP0338005) and Ministry of Science and Technology of Korea (M10302-00-0063) supported aspects of this study. This work was supported by the research fund of the Kongju National University in 2008 .

\section{References}

Arkani-Hamed, J., Differential reduction to the pole: Revisited, Geophysics, 72, 613-620, 2007.

Artyushkov, E. V., Stresses in the lithosphere caused by crustal thickness inhomogeneities, J. Geophys. Res., 78, 7675-7708, 1973.

Bouchon, M., The complete synthesis of seismic crustal phases at regional distances, J. Geophys. Res., 87, 1735-1741, 1982.

Braile, L. W. and C. S. Chiang, The continental Mohorovicic discontinuity: Results from near-vertical and wide-angle seismic reflection studies, in Reflection seismology: A Global Perspective, edited by Barazangi, M. and L. Brown, AGU Geodynamics Series, 13, 257-272, 1985.

Campillo, M., M. Bouchon, and B. Massinon, Theoretical study of the excitation, spectral characteristics, and geometrical attenuation of regional seismic pluses, Bull. Seismol. Soc. Am., 74, 79-90, 1984.

Cordell, L. and P. Taylor, Investigation of magnetization and density of a North Atlantic Seamount using Poisson's Theorem, Geophysics, 36, 919-937, 1971.

Culotta, R. C., T. Pratt, and J. Oliver, A tale of two sutures: COCORP's deep seismic surveys of the Grenville Province in the eastern U.S. Midcontinent, Geology, 18, 646-649, 1990.

Fuller, M. D., Expression of E-W fractures in magnetic surveys in parts of the U.S.A, Geophysics, 29, 602-622, 1964.

Gupta, I. N. and D. L. McLaughlin, Attenuation of ground motion in the eastern United States, Bull. Seismol. Soc. Am., 77, 366-383, 1987.

Hansen, M. C., The geology of Ohio-The Precambrian, Ohio Geology, Ohio Div. Geol. Survey, Winter, 1-6, 1996.

Hernandez, O. and R. R. B von Frese, Isostatically disturbed terrains of the northwestern Andes Mountains from spectrally correlated free air and gravity terrain data, Earth Sciences Res. J., 10(2), 131-146, 2006.

Heyl, A. V., the $38^{\text {th }}$ parallel lineament and its relationship to ore deposits, Economic Geology, 67, 879-894, 1972.

Kennett, B. L. N., On regional S, Bull. Seismol. Soc. Am., 75, 1077-1086, 1985.

Kim, H. R., Antarctic Lithospheric Anomalies from Ørsted Satellite and Near Surface Magnetic Observations, (Unpubl. Ph.D.-dissertation),
Dept. of Geological Sciences, The Ohio State University, 160 pp, 2002. Kim, J. W., R. R. B von Frese, and H. R. Kim, Crustal modeling from spectrally correlated free-air and terrain gravity data A case study of Ohio, Geophysics, 65(4), 1057-1069, 2000.

Langel, R. A. and W. J. Hinze, The Magnetic Field of the Earth's Lithosphere: The Satellite Perspective, pp. 429, Cambridge University Press, 1998.

Lemoine, F. G., D. S. Chinn, S. M. Cox, J. K. Factor, S. C. Kenyon, S. M. Klosko, S. B. Luttcke, T. R. Olson, E. C. Pavlis, N. K. Pavlis, R. H. Rapp, M. H. Torrence, R. G. Trimmer, Y. M. Wang, and R. G. Williamson, The development of the joint NASA GSFC and the National Imagery and Mapping Agency (NIMA) Geopotential Model EGM96, National Aeronautics and Space Administration (NASA), Scientific and Technical Information Office, NASA Technical Paper 01488341, NASA/TP-1998206861, 1998.

Levander, A., USArray design implications for wavefield imaging in the lithosphere and upper mantle, The Leading Edge, 22, 250-255, 2003.

Lucius, J. E. and R. R. B. von Frese, Aeromagnetic and gravity anomaly constraints on the crustal geology of Ohio, Geol. Soc. Am. Bull., 100, 104-116, 1988.

Maus, S., M. Rother, K. Hemant, C. Stolle, H. Lühr, A. Kushinov, and N. Olsen, Earth's lithospheric magnetic field determined to spherical harmonic degree 90 from CHAMP satellite measurements, Geophys. J. Int., 164, 319-330, 2006.

Mayhew, M. A., H. H. Thomas, and P. J. Wasilewski, Satellite and surface geophysical expression of anomalous crustal structure in Kentucky and Tennessee, Earth Planet. Sci. Lett., 58, 395-405, 1982.

Meltzer, A., EarthScope: Opportunities and challenges for earth-science research and education, The Leading Edge, 22, 268-271, 2003.

Moores, E. M., Southwest United State-East Antarctica (SWEAT) connection-A hypothesis, Geology, 19, 425-428, 1991.

Olsen, K. H. and L. W. Braile, Seismograms of explosions at regional distances in the Western United States: Observations and reflectivity method modeling, in Identification of Seismic Sources Earthquake or Underground Explosion, edited by Husebye, E. S. and S. Mykkeltveit, p. 453-466, D. Reidel Publishing Co., 1981.

Owens, T. J. and J. Fowler, New instrumentation drives discovery of the earth's deep interior, The Leading Edge, 22, 220-223, 2003.

Pratt, T., R. Culotta, E. Hauser, D. Nelson, L. Brown, S. Kaufman, J Oliver, and W. Hinze, Major Proterozoic basement features of the eastern Midcontinent of North America revealed by recent COCORP profiling, Geology, 17, 505-509, 1989.

Purucker, M., B. Langlais, N. Olsen, G. Hulot, and M. Mandea, The southern edge of cratonic North America: Evidence from new satellite magnetometer observations, Geophys. Res. Lett., 29(15), 8000, doi:10.1029/2001GL013645, 2002.

Schnetzler, C. S. and R. J. Allenby, Estimation of lower crust magnetization from satellite derived anomaly field, Tectonophysics, 93, 33-45, 1983.

Schwartz, S. Y. and D. H. Christensen, The 12 July 1986 St. Marys, Ohio earthquake and recent seismicity in the Anna, Ohio seismogenic zone, Seismol. Res. Lett., 59, 57-62, 1988.

Seeber, L. and J. G. Armbruster, Recent and Historic Seismicity in Northeastern Ohio: Reactivation of Precambrian Faults and the Role of Deep Fluid Injection, U.S. Nuclear Regulatory Commission Rept, 1988.

Smith, A. G., A. M. Hurley, and J. C. Briden, Phanerozoic Palaeocontinental World Maps, Cambridge University Press, 1981

Starich, P. J., W. J. Hinze, and L. W. Braile, The south-central U.S. magnetic anomaly, Soc. Expl. Geophys., $55^{\text {th }}$ Annual International Meeting and Exposition, Technical Program, 204-206, 1985.

Taylor, P. T. and J. J. Frawley, Magsat anomaly data over the Kursk region, USSR, Phys. Earth Planet. Inter., 45, 255-265, 1987.

Thomas, H. H., Petrologic models of the northern Mississippi Embayment based upon satellite magnetic and ground based geophysical data, Earth Planet. Sci. Lett., 70, 115-120, 1984.

USGS, Advance National Seismic System (ANSS), (http://earthquake. usgs.gov/research/monitoring/anss/), 2006.

Vargas, C. A. and J. P. Duran, State of stress of northwestern South America, Earth Sciences Res. J., 9(1), 41-49, 2005.

von Frese, R. R. B., W. J. Hinze, and L. W. Braile, Spherical earth gravity and magnetic anomaly analysis by equivalent point source inversion, Earth Planet. Sci. Lett., 53, 69-83, 1981a.

von Frese, R. R. B., W. J. Hinze, L. W. Braile, and A. J. Luca, Spherical earth gravity and magnetic anomaly modeling by Gauss-Legendre Quadrature integration, J. Geophys., 49, 234-242, 1981 b.

von Frese, R. R. B., W. J. Hinze, and L. W. Braile, Regional North Amer- 
ican gravity and magnetic anomaly correlations, Geophys. J. R. Astr. Soc., 69, 745-761, 1982.

von Frese, R. R. B., W. J. Hinze, R. Olivier, and C. R. Bentley, Regional magnetic anomaly constraints on continental breakup, Geology, 14, 68$71,1986$.

von Frese, R. R. B., M. B. Jones, J. W. Kim, and W. S. Li, Spectral correlation of magnetic and gravity anomalies of Ohio, Geophysics, 62, 365-380, 1997a.

von Frese, R. R. B., J. W. Kim, L. Tan, D. E. Alsdorf, C. A. Raymond, and P. T. Taylor, Satellite-measured magnetic anomaly fields of the Antarctic lithosphere, in The Antarctic Region: Geophysical Evolution and Processes, edited by Ricci, C. A., pp. 1105-1110, Terra Antarctica Publ., 1997b.

Wagoner, R. H. and J.-L. Chenot, Metal Forming Analysis, 376 p., Cambridge University Press, 2001.
Wesson, R. L. and C. Nicholson (eds), Studies of the January 31, 1986, Northeastern Ohio earthquake: U.S.Geological Survey Open-File Report 86331, 131 p., 1986.

Williams, H. and R. D. Hatcher, Jr., Appalachian suspect terrains, in contribuction to the tectonics of mountain chains, edited by Hatcher, R. D., Jr., Williams, H. and Zietz, I., Geo. Soc. Am. Mon., 158, 33-53, Washington, 1983.

Zoback, M. L., Stress field constraints on intraplate seismicity in eastern North America, J. Geophys. Res., 97, 11761-11782, 1992.

R. R. B. von Frese, J. W. Kim, O. Hernandez, H. R. Kim (e-mail: kimhr@kongju.ac.kr), and M. F. Asgharzadeh 